\title{
SINONIMIAS COLOMBINAS, SINONIMIAS LASCASIANAS
}

\author{
JosÉ LUIS RIVAROLA \\ Università di Padova
}

\section{Para Kurt Baldinger}

Aun a riesgo de rebajar el inicio de la presente reflexión al nivel del lugar común, se impone la referencia - destinada a encauzar el sentido de lo que expondré en las páginas siguientes - a las dificultades textuales que presenta el Diario del primer viaje colombino, dificultades en gran parte derivadas de su carácter de texto ambiguo y heterogéneo, producto - en la única versión conservada - de, por lo menos, dos enunciadores, y de distintos momentos de enunciación, que no siempre es posible discriminar ${ }^{1}$. En primer lugar, como es bien sabido, el texto que el Padre Las Casas utilizaba para confeccionar su versión del Diario, hecha de cita parcial, con visos de respetuosa literalidad (que, sin embargo, no debía de excluir, cuando menos, un barniz de normalización lingüística) ${ }^{2}$, de resumen y de comentario tanto interno como externo - todo ello en fortísima imbricación-, era no

\footnotetext{
1 Para la inmensa bibliografía colombina remito a Simonetta Conti, Bibliografia colombiana 1793-1990, Genova, Casa di Risparmio di Genova e Imperia, 1990, que contiene un útil índice temático y me exime, así, de referencias exhaustivas. Además, hay que considerar, ciertamente, lo publicado en los últimos años, como consecuencia del Quinto Centenario. En el curso de este artículo mencionaré solamente aquellos trabajos que se relacionan directamente con algún aspecto de la argumentación.

2 Sobre la fidelidad de la reproducción de Las Casas, cuando el dominico marca la literalidad, hay opiniones encontradas. Muy crítico a este respecto se muestra David Henige, «To read is to misread. To write is to miswrite. Las Casas as transcriber», en René Jara y Nicolás Spadaccini (ed.), Amerindian Images and the Legacy of Columbus, Minneapolis, University of Minnesota Press, 1992, págs. 182-197. Cf. también Margarita Zamora, «Todas son palabras formales del Almirante», Hispanic Review, 57, 1989, págs. 198-229. En muchos casos, las críticas provienen de un criterio anacrónico de los conceptos de cita y literalidad. En cualquier caso, la literalidad de las citas no estaba reñida con la intervención correctora de fenómenos idiomáticos, más aun cuando se trataba, como en el caso de Colón, de un hablante que no tenía el español como lengua materna. Que el P. Las Casas corrige en parte la ano-
} 
un texto autógrafo de Colón, sino una copia (o una copia de copias) ${ }^{3}$, reconocida por el dominico como defectuosa en varias ocasiones que suscitan su perplejidad respecto del sentido del discurso ${ }^{4}$.

Pero tales lugares textuales incriminados podrían reflejar, no sólo la inepcia o la voluntad enmendatoria del amanuense, sino también intervenciones del enunciador originario sobre su propio texto inicial, que habría sometido (¿una?, ¿varias veces?) a revisión y corrección. De que Colón releía su texto como parte de su propio proceso de escritura no cabe la menor duda, vistos los numerosos casos de referencias con preciso carácter anafórico destinadas, en ocasiones, a validar la verdad de ciertos enunciados valorativos, cuando podían entrar en conflicto con otros anteriores ${ }^{5}$; lejanos de toda transparencia, en cambio, se presentan aquellos casos de posibles correcciones específicas, los cuales abren un amplio espacio para la especulación. Como ejemplo puede examinarse el que se encuentra en el registro del 17 de noviembre, vertido así por Las Casas en la parte que aquí interesa:

hallo nuezes grandes delas <testado grandes> de yndia creo que dize / y ratones grandes delos de yndia tambien $/^{6}$

malía lingüística colombina resulta claramente de una comparación de las citas literales que se hallan en el Diario con los autógrafos del Almirante. Sobre el español de Colón puede verse ahora, con un planteamiento adecuado a la realidad de los testimonios, Juan Gutiérrez Cuadrado, "Volviendo sobre la lengua de Colón", en Theodor Berchem y Hans Leitenberger (coords.), Lengua y Literatura en la época de los Descubrimientos, Valladolid, Junta de Castilla y León, 1992, págs. 221-245.

3 Cf. a este propósito David Henige, In search of Columbus. The sources for the first voyage, Tucson, The University of Arizona Press, 1991. Henige señala, inclusive, la posibilidad de que la copia utilizada por Las Casas para su versión tuviera ya un carácter de resumen (pág. 23).

${ }^{4}$ Cf. los registros del 8 y del 30 de octubre, y también el del 13 de enero. Véase asimismo el del 2 de noviembre en la Historia de las Indias de B. de Las Casas (citado en adelante como $H I$, a partir de la ed. de Juan Pérez de Tudela Bueso, Madrid, Biblioteca de Autores Españoles, 1957, tomos I y II; el mencionado registro se halla en la pág. 160a).

${ }^{5}$ Véase, como ejemplo, la declaración contenida en el registro del 21 de diciembre.

${ }^{6}$ Cito (salvo dentro de mi propio discurso) con criterio paleográfico estricto (solo intervengo en la resolución de formas abreviadas por medio de cursiva y en la introducción de apóstrofos), según mi propia lectura, basándome en la reproducción facsimilar del manuscrito publicada por Manuel Alvar (Diario del Descubrimiento, Madrid, Ediciones del Excmo. Cabildo Insular de Gran Canaria, 1976) y teniendo en cuenta las excelentes ediciones paleográfica y crítica de Alvar mismo (op. cit.) y la paleográfica de Oliver Dunn y James E. Kelley, Jr., The Diario of Christopher Columbus's First Voyage to America 1492-1493, University of Oklahoma Press, 1989. Indico entre paréntesis agudos las correcciones o tachaduras, poniendo en cursiva mis propias indicaciones; en cambio las barras simples provienen del manuscrito, así como también algunos signos que tienen la forma de paréntesis curvos. Entre paréntesis cuadrados doy alguna aclaración sobre el sentido del texto citado, pongo puntos suspensivos que indican una parte suprimida en la cita o añado un sic. 
Sobre el margen izquierdo del manuscrito, a la altura de la primera línea transcrita, Las Casas anota: «hutias devian de ser» ${ }^{7}$. Ahora bien, la inseguridad que expresa el dominico acerca de la literalidad del texto que tiene como base de su escritura se concentra en ese «creo que dize»; pero se puede ir más allá de la simple interpretación basada en la dificultad de descifrar la letra del amanuense. Es lo que hace Juan Gil, quien piensa en la posibilidad de que Las Casas haya tropezado con un pasaje en el que la dificultad gráfica de la copia que usaba el dominico fuese resultado de una «corrección enrevesada» que el autor de dicha copia había encontrado en el original colombino ${ }^{8}$. Colón, según esta hipótesis, habría retocado su texto originario en lo que respecta al modo de referirse a tales «ratones», y lo habría hecho cinco años más tarde, luego de leer a Marco Polo - no antes de 1498, en el ejemplar que le había conseguido el mercader de Bristol John Day -, ya que el veneciano habla en dos ocasiones de los ratti Pharaonis, identificados en una apostilla, probablemente colombina, con las $h u$ tías de La Española ${ }^{10}$ (como también apostilla Las Casas en el referido pasaje del Diario). Pero cabría preguntarse con cierta sorpresa, ya ubicados en este ámbito hipotético, por qué Colón - puesto a introducir precisionesno aprovechó para incluir el nombre indígena, anotado al hilo de la lectura de la traducción latina del libro de Marco Polo.

Sea como haya surgido la dificultad textual aludida por Las Casas, lo cierto es que es excepcional la presencia de una explícita marca de inseguridad, por parte del dominico, respecto del texto de base. Para la explicación de la mayor parte de los errores y vacilaciones, tal como se expresan en las continuas tachaduras y correcciones interlineadas o marginales del manuscrito lascasiano - errores y vacilaciones motivados en gran parte por la tensión constante entre el propósito de copiar y el propósito de refundir- estamos librados a una reconstrucción basada en el examen interno de tales marcas del proceso de escritura, en su eventual correlación con pasajes equivalentes de otras fuentes y en la consideración de ciertos fenómenos

\footnotetext{
${ }^{7}$ Las hutías eran una especie de roedores, que los españoles comparaban con conejos o ratones (cf. Georg Friederici, Amerikanistisches Wörterbuch, Hamburg 1960, s.v.). No obstante esta identificación, en el pasaje correspondiente de la HI, Las Casas establece la relación con los guanamiquinajes, «que eran unos animales como perrillos» (pág. 168a).

${ }^{8}$ Cf. Juan Gil, «Introducción» a El Libro de Marco Polo/Las Apostillas a la Historia Natural de Plinio el Viejo, Madrid, Alianza, 1992, pág. XXXVII.

${ }^{9}$ Cf. al respecto la obra mencionada en la nota anterior.

${ }^{10} \mathrm{La}$ alusiones de Polo a estos ratones se hallan en I, 57 y III, 47. Un razonamiento similar aplica Gil a las «nueces de la India», nombre que el traductor al latín del libro poliano da a la palma cocotera. El «probablemente» que añado a la atribución colombina de la apostilla en cuestión alude a las reconocidas dificultades que surgen cuando se trata de distinguir la grafía de los diversos anotadores del texto del Milione.
} 
lingüísticos. Como ejemplo de los problemas que presenta tal explicación y de las implicaciones que puede comportar, me serviré de parte de la frase inicial del registro del 6 de agosto, la cual ya nos pone, además, en la pista de lo que constituye el tema central de la presente contribución. El manuscrito de Las Casas que conserva el texto del Diario abre así la singladura mencionada:

<testado Se le quebro> Salto / o desencasose el governario a la caravela pinta

El primer problema que se plantea es el de la parte tachada, con la que se da cuenta del accidente sufrido por el timón ${ }^{11}$ de La Pinta. Nótese que constituye un inicio frustrado, que ha debido ser retomado luego por medio de una pareja sinonímica. Las preguntas que surgen naturalmente son las siguientes: ¿encontró Las Casas se le quebró en el manuscrito del que copiaba y resumía, lo reprodujo y luego lo tachó porque consideró que en la duplicación verbal posterior se expresaba más propiamente el daño en cuestión? ¿Se le quebró es una invención lascasiana para dar cuenta de un hecho al que en el texto del que copiaba se aludía de otro modo, eventualmente con saltó? Me inhibo de otras formulaciones interrogativas que podrían parecer una invitación a ensayarse en el arte adivinatorio. Lo que merece la pena, en cambio, es explicar la naturaleza de la relación entre los verbos en juego y de allí tratar de elaborar una hipótesis plausible o una especulación controlada. Parece claro que quebrarse no es el vocablo más propio para identificar lo ocurrido con el timón de La Pinta, ya que no se había verificado una rotura sino más bien una dislocación. Sin embargo, bien se puede pensar que el verbo podía tener en el uso coloquial un valor más general y menos preciso, y que fuese sinónimo con este valor, como ocurre parcialmente hoy con romperse ${ }^{12}$, de estropearse. Si esto era así, resulta poco plausible atribuir a Las Casas el se le quebró del texto, es decir,

\footnotetext{
${ }^{11}$ A propósito de governario, no sé que se haya dado una explicación de esta forma que aparece en el Diario alternando con governalle, término, de origen catalán, que se usaba en castellano (governalle se emplea tres veces, una el 7 de agosto y dos el 25 de diciembre; governario aparece también tres veces, el 6 y el 8 de agosto, y el 25 de diciembre). Quizá se trate de una intervención de Las Casas, quien utiliza sólo governario en los pasajes correspondientes de la $H I$ y en algún otro sin correspondencia con el Diario; el dominico podría haber reconocido, en efecto, el carácter no castellano de la forma governalle, avanzando, ya en su versión del Diario - aunque de modo aun incoherente - la propuesta castellanizadora de corte cultista que luego haría efectiva de modo regular en la HI. Julio F. Guillén Tato consideró la forma governario como un "posible italianismo», pero no se sabe sobre qué base (La parla marinera en el Diario del primer viaje de Cristóbal Colón, Madrid, Instituto Histórico de la Marina, 1951, s.v.).

${ }^{12}$ Sobre todo con referencia a máquinas o mecanismos. Uso similar existe en italiano.
} 
atribuirle la sustitución de un uso más propio por otro menos propio. Así, lo ocurrido en este tramo textual parecería poder corresponder a una respuesta afirmativa al primer interrogante planteado arriba. En efecto, frente al presumible se le quebró de la fuente, se puede pensar que Las Casas lo copia, pero inmediatamente luego percibe que no se ajusta, según él, a la naturaleza del hecho, o, por lo menos, considera que hay una forma más propia de referirse a esta. Quizá en dicha fuente se hallaba también saltó coordinado con se le quebró. Si esto fue efectivamente así, Las Casas habría notado que saltar era un verbo adecuado, sí, para describir el incidente, en todo caso más que quebrar, a pesar de lo cual habría preferido - siguiendo una tendencia que se encuentra a lo largo de su prosa y que más adelante se verá con claridad - poner esta voz en correlación explicativa con otro vocablo sinónimo o parasinónimo, que servía para acotar con precisión la naturaleza del hecho: desencasose ${ }^{13}$. ¿Hay indicios que apuntan en la dirección señalada? Me parece que sí, aunque débiles. Cuando el 7 de agosto vuelve a presentarse el tropiezo con el timón de la carabela, el texto del Diario ya sólo consigna saltar: «tornose a saltar el governalle a la pinta». Sea que este verbo provenga de la fuente usada por Las Casas, sea que proceda del dominico, lo cierto es que este último lo considera ya -en el transfondo del cercano contexto precedente- suficiente para dar cuenta del hecho y lo consigna sin apoyo sinonímico.

En este punto se impone, sin embargo, echar una mirada a la Historia de las Indias. Cuando Las Casas reelabora el texto del Diario para convertirlo a la estructura retórica de su propio discurso, opta por mantener la duplicación verbal del registro del 6 de agosto, pero invirtiendo el orden y agregando a saltar una especificación que acentuaba la equivalencia sinonímica con desencasose: "desencasose o saltó de sus hembrillas el gobernario a la carabela Pinta» (HI I, 128a). Una interpretación posible de esta reformulación es que saltar solo, encontrado por Las Casas quizá ya en el texto del que se servía para su versión del Diario, no fue considerado por él lo suficientemente preciso como para aparecer así en la escritura más elaborada de su propia obra, razón por la cual optó por anteponer el verbo que comportaba una lexicalización más específica de la acción y por duplicar la referencia con el verbo más general, pero con un añadido también especificador.

Para finalizar el examen de este pasaje, que muestra emblemáticamente algunos de los problemas que presenta el texto del Diario, vale la pena anotar que la versión italiana hecha por Alfonso de Ulloa del libro de Hernando Colón dedicado a su padre presenta en este punto una formulación

${ }^{13}$ Sobre este verbo, probablemente un italianismo en español, cf. DECH s. caja. 
que permite establecer que el original castellano perdido de dicha traducción concuerda en este punto con la Historia de las Indias de Las Casas y no con el texto del Diario copiado por este. En efecto, en «ad una delle caravelle della compagnia chiamata Pinta saltarono fuori le fencine del timone», la porción impresa en negrita corresponde exactamente a «saltó de sus hembrillas el gobernario a la carabela Pinta» ${ }^{14}$. En cualquier caso, nótese que el verbo saltar se mantiene constante en los tres textos que se remiten, de un modo $u$ otro, al texto de Colón sobre el primer viaje descubridor.

El análisis de la frase inicial del registro del 6 de agosto nos ha puesto frente a una cuestión que reiteradamente se le plantea al lector a lo largo del Diario: la presencia de parejas de vocablos sinónimos o parasinónimos ${ }^{15}$, de duplicaciones léxicas como la representada por el caso que acabamos de ver. El mismo registro en cuestión, que se inicia con un ejemplo que he calificado de emblemático del tema bajo examen, continúa del siguiente modo:

donde yva martin alonso pinçon a lo que se creyo/o sospecho por industria de vn gomez Rascon y Xristoval quintero cuya era la caravela porque le pesava yr aquel viaje/ y dize el almirante que antes que partiesen avian hallado en çiertos reveses y grisquetas como dizen a los dichos

Nuevamente, como se ve, dos duplicaciones léxicas, en las cuales vale la pena detenerse. En el caso de la primera, el segundo término, sospechar, parece fijar el alcance semántico del primero: en efecto, creer aquí significa «sospechar» y no «estar seguro», ya que, como resulta de todo el contexto, hay sólo indicios para incriminar a dichos personajes. El uso de creer con el valor de «sospechar» o «tener por verosímil» debe de haber estado extendido en todas las épocas ${ }^{16}$, no obstante lo cual podía, probablemente, abrir un cierto margen de ambigüedad en determinados contextos. Esta ambigüedad es la que habría motivado a Las Casas a agregar el otro verbo, sin decidir-

\footnotetext{
${ }^{14}$ Cito por la ed. de R. Caddeo, Le Historie della vita e dei fatti di Cristoforo Colombo, Milano, Istituto Editoriale Italiano, 1957, I, pág. 99. Sobre la problemática relación entre la HI de Las Casas y la obra de Hernando, la opinión de Alejandro Cioreanescu va en dirección de la dependencia de la segunda respecto de la primera (Primera biografia de Cristóbal Colón, Fernando Colón y Bartolomé de Las Casas, Tenerife, 1960).

${ }^{15}$ Utilizo sinonimia en un sentido laxo, sin entrar en la discusión teórica sobre el concepto. En cualquier caso, considero que entre los sinónimos, descontada la base referencial común, puede haber diferencias, tanto en el plano simbólico-representativo, cuanto en el sintomático-apelativo (cf. la nota 26). Cuando las diferencias en el primer plano mencionado son más notorias se trata de parasinónimos.

${ }^{16} \mathrm{Cf}$. R. J. Cuervo, Diccionario de construcción y régimen de la lengua castellana, s. creer, pág. 589a; allí se encontrarán varios testimonios de la acepción «tener por verosímil o probable». Cf. también el siguiente texto tomado de Juan de Ávila $(\dagger 1569)$ : «Otras veces suelen los santos y el uso común de hablar, llamar creer al tener una opinión causada de razón y conjeturas».
} 
se todavía a suprimir el primero. A ciencia cierta no se puede saber, como es obvio, si este esclarecimiento semántico proviene del propio Colón o de Las Casas. Tiendo más bien a lo segundo, basándome en el hecho de que Las Casas, no obstante su marcado gusto por las duplicaciones léxicas-que veremos luego-, en su versión de la Historia de las Indias mantiene sólo el segundo verbo («y según se sospechó»), lo cual permite inferir que no consideraba pertinente la equivalencia, ni aun en el nivel de artificio retórico, y que tal duplicación sólo le resultaba aceptable como parte de un trabajo de taller, como el que revela la escritura de la copia del Diario ${ }^{17}$. Si esto es así, podemos reconstruir el proceso de escritura lascasiano de este modo: luego de copiar el se creyó de la fuente, F. Bartolomé se sintió inclinado a precisar el valor semántico del verbo y agregó o sospechó; pasado el momento de la copia del Diario, y sintiéndose con menos ataduras respecto de la fuente que reelaboraba, dejó en la Historia de las Indias solo la forma léxica que consideraba ser el uso propio ${ }^{18}$.

El siguiente caso presenta rasgos un tanto diversos. En primer lugar, la pareja aparece coordinada por $y$ : si bien esto podría ser interpretado en el sentido, no de una explicitación del primer término (por más que inevitablemente también lo sea), sino como un añadido que amplía el espacio referencial, no debe atribuirse demasiada importancia a la diferencia entre la coordinación con una conjunción $\mathrm{u}$ otra, pues ambas construcciones son a menudo equivalentes en este tipo de duplicaciones. Más significativo es el hecho de que el segundo término, a saber, grisquetas, aparezca seguido de un comentario metalingüístico, como dizen, que parece referirse a él. No se puede excluir que Las Casas esté copiando aquí un comentario del propio Colón, pero da la impresión de que el como dizen proviene de Las Casas, en cuya escritura abunda este tipo de marcas ${ }^{19}$. Más difícil es pronunciarse

17 El texto italiano de Hernando Colón presenta en este pasaje un solo verbo, a saber, $d u$ bitare: «perciocchè dubitava cotal caso essere avenuto per astuzia o malignità del padrone...» (Historie, pág. 99).

${ }_{18}$ Naturalmente, también se puede pensar en otra opción: en que la sinonimia provenga de Colón y que Las Casas, respetándola en un primer momento, la redujera en la $H I$. Sin embargo, además del hecho de que del examen de la escritura colombina no resulta que las duplicaciones sean un recurso digno de ser notado, tratándose de palabras de uso común sería menos explicable aun la sinonimización. Pero no hay duda de que el tramado de estas consideraciones no es absolutamente tupido: podría pensarse, asimismo, que, si la pareja de vocablos proviene de la pluma del Almirante, los dos verbos no estén en relación de sinonimia, sino de disyunción («o se creyo o se sospecho»), y que Las Casas suprimiera el primer término de la disyunción por considerar que no había indicios suficientes para asegurar la responsabilidad de Gómez y de Quintero, sino solo para sospechar de ellos.

${ }^{19}$ Bastará el siguiente ejemplo en representación de muchos otros: «Proveyó luego el rey Guacanagarí con gran diligencia, mandando que una canoa esquifada de remos, como dicen los marineros, [fuese] luego a buscar la carabela» (HI I, pág. 199a). 
respecto de grisquetas. ¿De Colón o de Las Casas? Aquí en favor de la segunda posibilidad viene en ayuda una consideración lingüística. El significado y el étimo de la voz han sido aclarados por Manuel Alvar en su edición crítica del Diario ${ }^{20}$ : "Grisquetas 'disputas'. La forma transcrita en el Diario es la que se esperaría en una evolución normal castellana. Del antiguo griesgo salió grisgo, documentado en Villasandino (...) La etimología, $\mathrm{g} \mathrm{r}$ a e c i s c u hay que culparla a la fama que tuvieron los griegos de ser gente pendenciera y reñidora; así, por ejemplo, griego era 'tahur, fullero'...». A esta precisa anotación cabe añadir lo siguiente: las formas antiguas de la voz presentan siempre una velar sonora en la última sílaba, mientras que la aparición de $-c a$ (gresca) sólo se documenta tardíamente ${ }^{21}$. A estar por la cronología, la forma que aparece en el Diario corresponde más a la época de Las Casas que a la de Colón ${ }^{22}$. Grisqueta, pues, parece ser un añadido del dominico, quien la retoma en la Historia de las Indias - aunque ya sin el comentario metalingüístico- en orden inverso respecto de reveses y por medio de una coordinación diversa: «y dice aquí Cristóbal Colón, que antes que partiesen, había tomado en ciertas grisquetas o reveses a los dichos» (pág. 128b).

En las páginas que siguen me propongo, una vez señalado, preliminarmente, el marco en el cual se desarrollarán las consideraciones siguientes, examinar, por una parte, ejemplos representativos de la sinonimia in praesentia del Diario - que los comentarios anteriores ilustran-y de la Historia de las Indias de Las Casas: tratándose de esta última obra, me refiero a la duplicación de un vocablo que aparece en el Diario; por otra parte, me ocuparé de la sinonimia in absentia, vale decir, de aquellos casos en los que un vocablo del Diario aparece sustituido por otro u otros en la Historia de las Indias. Por razones ligadas a la argumentación, sin embargo, dejaré para el final el análisis de la sinonimia presente en el Diario y me dedicaré previamente a la consideración de los otros dos casos mencionados.

Este examen me parece de interés para la historia de aquellas unidades del léxico español que serán puestas bajo la lupa, no sólo en lo que se refiere a su particular semantismo sino también respecto de su pertenen-

\footnotetext{
${ }^{20}$ Cf. la nota 6. La aclaración que transcribo se encuentra en el tomo II, pág. 19, nota 10.

21 A comienzos del siglo XVII, según Corominas, DECH, s. gresca.

22 Pero (el inevitable y saludable pero de este tipo de conjeturas) tampoco se puede excluir que, de haber estado presente en el original colombino, la palabra hubiese sido modernizada por Las Casas, corrigiendo un eventual grisgueta de la fuente en grisqueta.
} 
cia a determinados niveles o registros; no obstante, hay otra motivación, de tipo crítico-textual, que se agrega a la anterior y la complementa, como ha podido deducirse también de la presentación introductoria. En efecto, en algunos de los análisis anteriores he formulado la hipótesis de que la duplicación léxica que se encuentra en algunos pasajes del Diario puede ser atribuida a Las Casas más que a Colón. Esta hipótesis podría extenderse a otros casos particulares en que tales parejas sinonímicas se atestiguan en la versión conservada del Diario gracias a la refundición de Las Casas.

Comenzaré, pues, con una consideración general de las duplicaciones léxicas o «desdoblamientos» (como también suelen llamarse), es decir, a lo que que aquí he introducido como casos de sinonimia in praesentia, tal como este fenómeno se encuentra en la tradición de la prosa española. Es un hecho bien conocido y bastante estudiado que tal procedimiento, si bien con antecedentes notorios en los siglos anteriores ${ }^{23}$, alcanza su apogeo en la prosa culta de los siglos XV y XVI, y llega aun al XVII ${ }^{24}$ : por prosa culta entiendo la prosa de arte (sea historiográfica, sea literaria, sea filosófica o doctrinal) y la prosa de tipo científico o técnico. En dicha prosa, en efecto, es abundantísima la utilización de parejas de vocablos en relación de coordinación (sea por medio de la conjunción $y$, sea a través de $o^{25}$ ) para cubrir léxicamente una determinada zona referencial. Ahora bien, esta copertura no resulta de una sola motivación ni se agota en un único efecto. Si en ciertos casos la duplicación léxica parece dar cauce a una suerte de compulsión estilística que huye del término único y se solaza estereotípicamente en un emparejamiento vocabular que no reviste mayor trascendencia semántica, en otros deriva de un propósito explicativo cuya sustancia - en último término, de carácter metalingüístico- los hace equivalentes de construcciones con explícito carácter epexegético que emplean fórmulas de conexión como que quiere decir, que es, etc. En cuanto a la relación entre las voces que aparecen en pareja en este tipo de prosa, los matices (eventual-

${ }^{23}$ Por ejemplo, en la prosa alfonsí o en los fueros. Es claro que no se trata, por lo demás, de un fenómeno que se manifiesta sólo en la prosa, aunque ahora me limitaré a ella. En poesía el uso también abunda, y es necesario estudiarlo en detalle.

${ }^{24}$ En el Quijote el uso de este tipo de duplicaciones llega a tener un matiz irónico o paródico que confirma hasta qué punto el 'binarismo léxico' era percibido por Cervantes como un estereotipo estilístico. Véase a este propósito Isaías Lerner, «Entre Cervantes y Ercilla: Quijote I, 8-9»", en Inés Carrasco y Guadalupe Fernández Ariza (eds.), El comentario de textos, Málaga (Anejo XVII de Analecta Malacitana), 1998, págs. 207-220, esp. 210 y 218.

${ }^{25} \mathrm{Cf}$. al respecto el bien documentado trabajo de Juan Gutiérrez Cuadrado, «Sobre algunos desdoblamientos léxicos del siglo XV», en Antiqva et nova Romania. Estudios lingüísticos y filológicos en honor de José Mondéjar en su sexagesimoquinto aniversario, Granada, Universidad de Granada, 1993, págs. 331-345. Remito a esta contribución para la bibliografia sobre el tema. 
mente, en dependencia del tipo de la motivación) pueden ser muy variados y oscilar entre una sinonimia que implica diversidad (complementaria) en el campo simbólico-representativo (o conceptual), y otra que atañe a factores de orden sintomático-apelativo ${ }^{26}$.

No es este el lugar para discutir la compleja fenomenología de las relaciones semánticas entre las unidades que conforman la dupla léxica, como tampoco para abordar el asunto del origen del fenómeno, que ha ocupado a numerosos estudiosos, entre los cuales hay quienes lo sitúan dentro del más general de la amplificatio clásica o quienes prefieren asignarle una posición más modesta, vinculada a la tradición de los ejercicios escolares medievales de acumulación de palabras afines ${ }^{27}$. Cualquiera que haya sido el origen y los caminos por los que ha llegado el fenómeno a los siglos que nos ocupan, conviene reiterar lo dicho anteriormente acerca de las motivaciones diversas, aunque no excluyentes entre sí, de su presencia en los textos: a veces el mayor ornato retórico, a veces la necesidad o el deseo de facilitar o asegurar la comprensibilidad del discurso, y otras más ${ }^{28}$.

Es el caso de la obra historiográfica del P. Las Casas. Como ilustración del aspecto ornamental de la duplicación, tomaré una decena de pasajes del prólogo de la Historia de las Indias, pero podría haber acudido a otras partes o a otras obras del autor, pues en todas ellas muestra su marcada predilección por este recurso estilístico. Téngase en cuenta que los casos que mencionaré a continuación - extraídos de apenas una pocas páginas- incluyen también aquéllos en los que la duplicación compromete palabras afines más que sinónimos, en un sentido más estricto, y que no dejo fuera casos de estructuras trimembres sobre la misma base conceptual; por lo demás, no citaré sólo casos de coordinación conjuncional sino también otros de yuxtaposición asindética:

\footnotetext{
${ }^{26}$ Con esta conceptuación y esta terminología hago referencia al modelo de signo lingüístico de Karl Bühler, tal como aparece expuesto en Sprachtheorie, Jena 1934 (trad. esp. Teoría del lenguaje, Madrid, Revista de Occidente, 2. ${ }^{a}$ ed. 1961). Para una aplicación de este modelo a la sinonimia cf. Kurt Baldinger, Teoría semántica, Madrid, Alcalá, 2. ${ }^{\text {a }}$ ed. 1977. En Klaus Heger, «La semántica lingüística», Lexis, V, 2, págs. 59-93, se encontrará el fundamento teórico para la reinterpretación de las diferencias diatópicas, diastráticas o diafásicas entre signos como componentes o factores sintomático-apelativos de su significado.

${ }^{27}$ Cf. a este respecto el punto de vista de Margherita Morreale en El Galateo español de Lucas Gracián Dantisco, Madrid, C.S.I.C., 1968, pág. 25.

${ }^{28}$ Así, por ejemplo, hay que contar, en algunos autores, con el deseo de ostentar un conocimiento idiomático que pone en juego sinónimos (o series mayores) con diferenciación diatópica o diastrática. Juan A. Frago, en un reciente trabajo, ha puesto de relieve cuán importante puede ser esta tendencia a la sinonimización para documentar las áreas de vigencia o los espacios sociales de determinados vocablos, ilustrándola con análisis de la obra de diversos escritores de los siglos XVI y XVII (cf. «Unidad y diversidad en el léxico español del Siglo de Oro», en C. Hernández Alonso (coord.), Homenaje al profesor Emilio Alarcos García, Valladolid, Junta de Castilla y León/Universidad de Valladolid, 1998, págs. 71-90).
} 
...algunos, sintiendo en sí copia de polidas y limadas palabras, dulzura y hermosura de suave decir, deseosos de fama y de gloria, para ganarla manifestando su elocuencia, eligen aqueste camino... (pág. 3a).

...de quien [la verdad] por dictamen de ley natural todos los hombres deben ser defensores, posponen por la declaración y defensión della la propia tranquilidad, descanso y reposo... (pág. 3ab).

...los coronistas griegos, los cuales, como fueron verbosos, elocuentes, abundantes de palabras, amicísimos de su propia estima y particular honor... (pág. 3b).

...los mismo griegos, los cuales, tanto en adulación con sus fictas y compuestas fábulas... (pág. 4a).

Ninguna pestilencia más perniciosa puede ofrecerse a los príncipes, según sentencia de Isócrates, que los aduladores o lisonjeros; porque quien al rey engaña con palabras blandas y suaves... (pág. 4a).

...porque tanto más los que fingen historias no verdaderas y que lisonjas contienen de los príncipes son perniciosos y nocivos... (pág. 4b).

...[las Historias] no siendo con verdad escriptas, podrán ser causa como los otros defectuosos y nocivos libros... (pág. 5a).

Donde asaz parece cuánta utilidad suele y puede proceder para la vida de los mortales de la verdadera y auténtica Historia (pág. 7a).

...tal es [el Paralelipomenon] y de tanta estima digno, que si alguno quisiese sin él alcanzar la ciencia de las Escripturas, él a sí mismo debría burlar y escarnecer; (pág. 8a).

...en aquestas Indias, cuántos y cuan inexpiables pecados se han cometido, cuánta ceguera y tupimiento en las consciencias... (pág. 10a).

Recorriendo las abundantes páginas de la Historia de las Indias se encontrará a cada paso muestras como las señaladas. También, sin embargo, otras en las que se puede percibir un propósito que va más allá del ornato retórico. Particularmente, cuando Las Casas duplica una unidad léxica del texto de Colón que toma como base para su narración del primer viaje en la Historia de las Indias, suele dominar una intención impregnada menos de retórica que de preocupación por el valor referencial de la voz o por la connotación implicada por el uso colombino, el cual parece sentirse como necesitado de un sinónimo equilibrador. A este respecto, debo aclarar que no trataré aquí de los casos obvios, en los que está en juego una equivalencia aloglótica, por más que ellos planteen varias cuestiones de difícil solución, 
que repercuten también en el juicio sobre el modo de intervención del dominico en el texto de Diario $^{29}$. Me ocuparé, pues, sólo de aquellos casos en los que están involucradas palabras hispánicas o románicas, dejando de lado los indigenismos americanos, que requieren un tratamiento aparte.

Comenzaré por examinar la sinonimia producida por Las Casas en la Historia de las Indias - reservando para el final, como he dicho, las que se encuentran en el Diario - y trataré de dilucidar la motivación semántica que la informa, además de la cual se puede siempre considerar la ornamental como valor agregado, dada la preferencia por estas duplicaciones en la prosa de la época, en general, y en la de Las Casas, en particular.

En verdad, no siempre es fácil esta dilucidación. Junto a casos relativamente obvios, vinculados al propósito de aclarar vocablos del lenguaje más o menos especializado de la marinería, por medio de otros con valor general que facilitan al lector no familiarizado con aquellos la comprensión del discurso, los hay muchos en los que, o parecen combinarse diversas causas, o estas se presentan brumosas e inciertas. A veces, por ejemplo, se tiene la impresión de que Las Casas, respetando la literalidad colombina en el uso de un vocablo, lo acota con otro que le parece más propio, o más actual, o más generalizado, o más comprensible. Pero si las fuentes de la época no son suficientemente informativas, estamos librados a especulaciones basadas en la conciencia actual de la lengua, las cuales, si no se controlan firme y cuidadosamente, pueden dar lugar a anacronismos vitandos.

Al navegar por el mar de los Sargazos el 16 de setiembre, Colón advierte grandes acumulaciones de hierba, a las que llama manadas. El texto dice así:

aqui començaron a ver muchas manadas de yerba muy verde que poco avia (segun le pareçia) que se avia desapegado de tierra

\footnotetext{
${ }^{29}$ Un caso ilustrativo, a este respecto, es el de canoa, que aparece por primera vez en una anotación de Las Casas al margen del lugar donde en el Diario se dice almadías (registro del 13 de octubre), y que luego alterna con esta última voz o aparece en sinonimia con ella (alguna vez con predicación explícita de la identidad, como el 26 de octubre, o acompañada de una expresión metalingüística sobre el carácter aloglótico de la equivalencia, como el 3 de diciembre: «almadías que los indios llaman canoas»). A agravar la ambigüedad de todo el asunto viene la siguiente referencia de Las Casas en HI I (158b): «Y entraron a más andar en sus canoas, que el Almirante llama almadías...», referencia que corresponde a un lugar del Diario (registro del 1 de noviembre) donde se habla, como otras tantas veces, de «almadías o canoas»).
} 
Me parece que en manada, si es que - como aquí- en el contexto en el que se emplea está referido a algo como hierba, se hace presente el semantismo del primitivo mano, y, por consiguiente, lo que puede predominar en dicho sustantivo es la acepción primera de «porción que se puede coger con la mano» y no la derivada, que con Autoridades podemos enunciar como «junta o concurrencia de personas u otras cosas». Ahora bien, esa presencia semántica del primitivo, y no obstante el refuerzo del adjetivo $m u$ chas en el texto colombino, parece atentar contra un principio de proporción entre el vocablo y el objeto referido; por lo menos esto es lo que sugiere el sinónimo usado por Las Casas, quien conocía por propia experiencia el fenómeno aludido por Colón, al punto que se permite una matización del color de la hierba y una referencia al temor que ella podía causar en los navegantes. En efecto, Las Casas agrega a (muchas) manadas el vocablo balsas (extendidas), único que emplea luego en un segundo momento. He aquí su texto:

Aquí comenzaron a ver muchas manadas o balsas extendidas de hierba verde, aunque más tiran a color amarilla y, porque ya se les iba haciendo el camino luengo y lejos la guarida, y habían comenzado a murmurar del viaje y de quien en él los había puesto, viendo estas balsas de hierba desde lejos y que eran muy grandes, comenzaron a temer no fuesen peñas o tierras anegadas, por lo cual se movieron a mayor impaciencia [...]pero visto que pasaban los navíos por ellas, perdieron por entonces, aunque no del todo, el temor (pág. 130a).

Pero, naturalmente, nuestra valoración de la insuficiencia referencial de manada en el Diario (que vemos confirmada por la duplicación lascasiana en este caso) podría ser, si no un espejismo, al menos una interpretación estimulada por el uso de la fórmula bimembre en la prosa del dominico.

Como he señalado, en numerosos casos el añadido sinonímico de Las Casas en la Historia de las Indias se verifica respecto de una voz perteneciente al lenguaje de la marinería. El sinónimo lascasiano puede anteceder o suceder a la voz del Diario: en el primer caso, Las Casas opta por identificar de inmediato el objeto referencial a través del vocablo general, de modo que la voz tomada del texto del Diario no tiene una función explicativa en el nivel semántico, sino solo la de informar sobre una diversa posibilidad designativa. En el segundo caso, el proceso se invierte: el vocablo técnico, que se toma del Diario, es aclarado por la palabra general. Estas 
dos formas de establecer la sinonimia ofrecen claves distintas sobre el proceso de la escritura lascasiana, tanto del Diario (en lo que este tiene de refundición debida a la pluma del dominico), cuanto de la Historia de las Indias, en las partes acodadas a aquel.

Ejemplo de la primera posibilidad es el siguiente pasaje, que transcribo en la versión del Diario y luego en la de la Historia de las Indias ${ }^{30}$ :

y vido una concha / o baia donde podian estar navio [sic] pequeños y no lo pudo encabalgar ${ }^{31}$ [el cabo] porqu'el viento avia tyrado del todo al norte $(31$ de octubre).

donde había una bahía para estar navíos pequeños, y no pudiendo doblar o encabalgar el dicho promontorio o cabo, por ser el viento Norte o cuasi Norte (HI I, pág. 158a).

Obsérvese, en contraste, los siguientes ejemplos, en los que antecede el vocablo técnico:

llego a la boca del rio y entro en vna cala al pie de aquel cabo (25 de noviembre).

Entró en una cala o rincón que hacía la mar $(H I \text {, pág. } 169 \mathrm{~b})^{32} \mathrm{~F}$.

anduvo el Almirante toda la noche la buelta de tierra y hizo tomar algunas delas velas y tener farol toda la noche (22 de noviembre).

el Almirante hizo tomar alguna de sus velas y tener farol o lumbre toda la noche (HI I, pág. 169a $)^{33}$.

vinole una turbiada que le rompio todas las velas (3 de marzo).

\footnotetext{
${ }^{30}$ De la sinonimia concha/bahía, eliminada por Las Casas en su texto, me ocupo más adelante.

${ }^{31}$ Sobre el significado preciso de encabalgar puede verse Guillén Tato, La parla... (cit.).

32 El 3 de diciembre, cuando Colón utiliza caleta, Las Casas renuncia a la sinonimia y prefiere la definición perifrástica: "caleta, que es una entrada angosta que hace el agua...» (HI I, pág. 174a). Sobre el origen y usos de cala y de caleta cf. DECH, s. cala.

${ }^{33}$ Para el carácter de marinerismo de tener farol cf. Alvar, Diario II, pág. 222, nota 444, con referencia a la Instrucción náutica de García Palacio, quien define así: «farol es la lumbre que va metida en la linterna grande con que se hace guia para que otras naves la sigan». Los pasajes citados arriba se refieren al momento en que La Pinta abandona la flota; cuando el 14 de febrero - de regreso ya las naves a Europa - La Pinta se pierde de vista a causa de la tormenta, se vuelve a usar la misma expresión en el Diario: «Desaparecio aunque toda la noche hizo faroles». En el pasaje correspondiente de la $H I$, Las Casas prefiere esta vez la explicación perifrástica y no la simple sinonimia: «...y desapareció... puesto que toda la noche hacía el Almirante hacer farol, que es mostrar lumbre como un hacha, y La Pinta con otro farol respondía...» (I, pág. 218a).
} 
vino una grande y súbita turbiada o golpe de tempestad que le rompió todas las velas (HI I, pág. 225a) ${ }^{34}$.

Frente a estos casos bastante claros respecto de la equivalencia semántica de las voces usadas, está este otro en el que Las Casas crea, a partir del vocablo empleado en el Diario, una sinonimia que pasa por alto el valor técnico que tiene el uso colombino, postulando una equivalencia sólo posible en la lengua común:

y dixoles el almirante a el [el maestre de la nao] y a los otros que halase el batel que trayan por popa: y tomasen un ancla / y la echasen por popa (25 de diciembre).

mandóle luego el Almirante y a todos los marineros que halasen el batel o barca que traían por popa, y que tomasen un ancla y la echasen por popa (HI I, pág. 194b).

Como resulta claramente del registro del 14 de diciembre y ha puesto de relieve Alvar ${ }^{35}$, el batel era el barco pequeño que llevaba o arrastraba la nao, mientras que la barca era la embarcación auxiliar empleada por la carabelas ${ }^{36}$.

En algún caso la motivación que parece percibirse en la duplicación lascasiana es quizá el halo arcaizante que ya envolvía al vocablo que aparece en el Diario. Así, el alfaneque empleado por el Almirante - quien inaugura con este uso un esquema de larga duración que permitía interpretar la diversidad indiana a partir de otra diversidad más familiar, la árabe ${ }^{37}$ — para

\footnotetext{
${ }^{34}$ Turbiada no es palabra documentada, que yo sepa, pero da la impresión de que se trata de un marinerismo. Alvar (Diario II, pág., 235, nota 468) piensa que se debe a un cruce entre los derivados de TURBo y de TURBIDUS.

${ }^{35}$ Cf. Diario II, pág. 56, notas 107 y 108.

${ }^{36}$ Hay varios casos en los que Las Casas, en vez de un sinónimo, que resultaría insuficiente como recurso explicativo, acude a la definición del término técnico: así, por ejemplo, en el caso de resaca (registro del 8 de diciembre en el Diario: Las Casas señala que «La resaca llaman los marineros las olas de la mar que quiebran o rebientan en tierra», HI I, pág. 179a), en el de garrar (registro del 10 de diciembre: Las Casas explica que «es arrastráronse [garráronse en la HI corresponde a hizole garrar del Diario] las anclas con el viento grande que hizo Nordeste..., HI I, pág. 180a), en los de lastre y lastrar (registros del 14, del 20 y del 23 de febrero, que Las Casas explica así: «que es la piedra y peso que ponen abajo porque [el navío] no se trastorne y ande, como calabaza, liviano» y «echar peso de piedra en las carabelas», respectivamente; $H I \mathrm{I}$, pág. 219a).

${ }^{37}$ Cf. a este propósito Jens Lüdtke, «Das indianische Fremde als arabisches Fremde», en Romanica arabica. Festschrift für Reinhold Kontzi zu seinem 70. Geburtstag, hrsgg. von Jens Lüdtke, Tübingen, G. Narr, 1966, págs. 481-493.
} 
aludir a las viviendas indígenas o a accidentes geográficos, aparece emparejado una vez por Las Casas al vocablo pabellón, con la mención del carácter adecuado de ambos usos figurativos:

ellas <interlineado las casas $>$ son todas a manera de alfaneques (17 de octubre).

son, como dice el Almirante, de hechura de alfaneques o pabellones, y ambas son buenas semejazas (HI I, pág. 151a) ${ }^{38}$.

Ahora, pabellón era una voz más moderna y actual en la época de la escritura de Las Casas, pues parece haber ingresado al español a fines del siglo xv. En todo caso, alfaneque requería ya una explicación; en otra ocurrencia de la voz, referida esta vez al Monte Cristo, Las Casas renuncia a pabellón y prefiere otra equivalencia:

el qual tiene forma de vn alfaneque muy hermoso (4 de enero).

el cual diz que tiene forma de un alfaneque o tienda de campo muy hermosa (HI I, pág. 205b).

Propósito similar de modernización léxica se observa en el reemplazo de espingarda del Diario (26 de diciembre) por escopeta o espingarda. Las Casas recupera el vocablo colombino en segundo lugar y acota: «que entonces así se llamaba» ${ }^{39}$.

El siguiente pasaje no parece permitir, hasta donde se me alcanza, otra interpretación que la resultante de atribuir al sinónimo lascasiano la pretensión de representar un uso de mayor propiedad para la designación del objeto referencial. Las diferencias pueden ser, no obstante, tan sutiles, que tampoco es descaminado pensar en un puro desdoblamiento ornamental. Se trata del siguiente pasaje en el que a humores del Diario Las Casas agrega vapores. Veamos:

\footnotetext{
38 Obsérvese la ambigüedad de la formulación, ya que el como dice el Almirante podría comprender la voz que en el Diario no se emplea.

${ }^{39}$ HI I, pág. 197b. Según el DECH, s.v. espingarda es un préstamo del francés documentado antes de 1479, mientras que escopeta es un italianismo que aparece por primera vez en 1517. En este campo del vocabulario, la mobilidad está vinculada, por cierto, a los progresos técnicos de los objetos designados, que probablemente ya no eran los mismos, a pesar de las equivalencias léxicas. Hago notar, como corroboración de esto, un pasaje de la narración del cuarto viaje, en el que Las Casas dice lo siguiente: «...y que en sintiendo el sonido de la escopeta, que agora llaman arcabuz...» (HI II, pág. 69b).
} 
porque estos dos tiempos son mas proprios porque los humores den mas lugar a ver mas lexos ( 7 de octubre).

porque aquestos son dos tiempos más proprios y convinientes para que los humores o vapores de la mar no impidan a ver más lejos mar o tierra que otros (HI I, pág. 137b).

$\mathrm{Si}$, ateniéndonos al testimonio de Autoridades, parece más apropiado referir humores a los «cuerpos vivientes», el testimonio más antiguo de Covarrubias apunta a un valor equivalente o muy próximo entre ambas voces, pues al definir justamente vapor dice: «es una exhalación o humor de la tierra o de la $\operatorname{mar})^{40}$.

En cambio, no me parece caber duda respecto de una interpretación orientada hacia la mayor propiedad del uso propuesto por Las Casas en el ejemplo siguiente, en el que el dominico convierte el hermosura del Diario en arreo y hermosura. El pasaje se refiere al interior de una casa indígena en Cuba:

hallaron muchas estatuas en figura de mugeres y muchas cabeças a manera de carantona muy bien labradas /. no se si esto tienen por hemosura / o adoran en ellas ( 29 de octubre).

hallaron dizque muchas estatuas en figura de mujeres y muchas cabezas bien labradas de palo; no supo si lo tenían por arreo y hermosura de casa o lo adoraban (HI I, pág. 156b).

Las Casas, como se ve, antepone ahora una voz tradicional más adecuada para «adorno», "gala» como es arreo y especifica el sustantivo hermosura, que en el texto del Diario resulta algo genérico y aproximativo ${ }^{41}$.

En todos los casos examinados hasta aquí hay un rescate de la literalidad del texto de base, ya que Las Casas repite un contenido expresado por un vocablo colombino, acodando a este un sinónimo. Pero, si bien con mo-

\footnotetext{
${ }^{40}$ Cf. Tesoro de la lengua castellana o española, México, Turner, 1983 [Madrid, 1611].

${ }^{41}$ Distinto, aunque significativo del gusto de Las Casas por las duplicaciones, es el caso en el cual a partir del siguiente texto del Diario: «Dize que todo era tan hermoso lo que via que no podia cansar los ojos de ver tanta lindeza» (3 de noviembre), Las Casas pasa a: «...no se le cansaban los ojos de ver tanta hermosura y lindeza...» (HI I, pág. 160b). Digo distinto porque la equivalencia ya viene propuesta en el Diario, si bien a través de voces de distinta categoría gramatical. Pero no se puede excluir, ni en el texto del Diario ni en el de la $H I$, un matiz diferencial vinculado al antiguo significado de lindo "puro». De hecho, tanto en uno como en otro texto, hay pasajes en los que lindo se usa con este valor.
} 
tivaciones análogas, el dominico opta en numerosas ocasiones por un procedimiento sustitutivo, como consecuencia del cual no queda huella del uso léxico del texto de base. La sustitución puede ser unimembre o bimembre. En ambos casos queda claro que a Las Casas no le parece digna de conservación la elección léxica que encuentra en su fuente, al punto que prefiere incluso renunciar al gusto estilístico por las parejas léxicas, pues es esto lo que implica la sustitución unimembre.

Un buen número de casos de sustitución afecta al léxico marinero. Comenzaré por un caso curioso en el cual el reemplazo ocurre una sola vez, y que muestra las vacilaciones de Las Casas y las diversas soluciones adoptadas frente a un término que le resulta ajeno. Se trata de una voz, abundantemente usada por Colón y que aparece con dos variantes fonéticas en el Diario, a saber, restinga y restringa. De incierto origen, quizá germáni$\mathrm{Co}^{42}$, designa un cordón de rocas salientes, cercanas a la costa. A veces Las Casas en la Historia de las Indias no sigue de cerca el pasaje correspondiente del Diario y, en consecuencia, no se confronta con este problema léxico. Pero cuando lo hace, la primera vez opta por sustituir restinga por arracife. Veamos los dos pasajes correspondientes:

Yo tenia de ver vna grande restinga de piedras que <testado cierra $><$ interlineado cerca $>$ toda aquella isla al rededor (14 de octubre).

Pero el Almirante por ir a ver un grande arracife de peñas que cerca toda la isla en redondo (HI I, pág. 147a).

El registro del 24 de noviembre en el Diario, no parafraseado por Las Casas en la Historia en el lugar en el que aparece restinga, nos ha dejado una huella de la incomodidad de Las Casas con la voz, ya que luego de su aparición hay un «que es» tachado, es decir, el comienzo de una iniciativa de explicación luego abandonada. En efecto, Las Casas en otros cuatro casos en que convierte a su Historia pasajes que contienen la palabra, acepta esta, aunque en dos de ellos apareándole el vocablo bajo (como sustantivo), que, no obstante aludir a un accidente diverso, como bien señaló $\mathrm{Alvar}^{43}$, sirve de contexto aclaratorio para restinga ${ }^{44}$.

Un interesante ejemplo de sustitución de marinerismos léxicos colombinos en serie isotópica nos lo ofrece la siguiente frase del registro del $11 \mathrm{de}$ octubre:

${ }^{42}$ Cf. al respecto el DECH s.v.

${ }^{43}$ Cf. Diario II, pág. 57, nota 110.

${ }^{44}$ Cf. HI I, pág. 205b y 207a. Se trata, pues, de casos similares a batel o barca, ya comentado, en el sentido de que se sinonimiza lo que no es sinónimo. 
amaynaron todas las velas y quedaron con el treo que es la vela grande sin bonetas y pusieronse a la corda temporizando hasta el dia <interlineado viernes>

Que Las Casas convierte del siguiente modo:

Así que, vista la tierra, bajaron todas las velas, quedándose los navíos con el papahigo, que dicen los marineros de la vela mayor, sacadas todas las bonetas, y anduvieron barloventeando hasta que fue el día. (HI I, págs. 140b-141a).

Amainaron, como se ve, se convierte en un bajaron de la lengua general ${ }^{45}$; treo - que aparece con una acotación explicativa en el Diario, probablemente debida a Las Casas ${ }^{46}$ - se convierte en otro marinerismo, seguramente más usual en el ámbito castellano, a saber papahigo, el cual queda marcado por Las Casas en su carácter de término especializado («que dicen los marineros $»)^{47}$; temporizando pasa también a otro marinerismo, barloventeando ${ }^{48}$.

Pero Las Casas puede optar también por la simple eliminación, si el texto colombino ofrece además del término eliminado otra alusión a la naturaleza del referente. Véase en el caso citado a continuación que Las Casas

45 Sobre amainar cf. DECH s.v. Se trata de una voz de origen incierto, documentada hacia mediados del siglo XV. No está claro si es un préstamo del italiano o si del español pasó a este último idioma. En cualquier caso, lo que interesa aquí es su carácter de término náutico, que viene confirmado por Covarrubias (Tesoro s.v.), quien dice: «Vale afloxar, alargando la mano, y es término náutico». También Autoridades consigna como primera acepción la náutica.

46 Treo es palabra de étimo poco claro (cf. DECH, s.v.), como también resulta poco claro el camino de su difusión. Corominas lo considera un catalanismo en castellano, pero la palabra se encuentra también en italiano, aunque sólo a mediados del siglo XVI, y en los dialectos (p. e. veneciano trevo). Ahora bien, la definición que da Autoridades («Voz náutica. Vela quadra que se arma solamente, quando hai mal temporal, o está el mar alborotado e tempestuoso, en las embarcaciones de poco bordo, que llevan velas latinas, o triangulares») no corresponde al uso colombino, como lo observa también Alvar (Diario II, pág. 47, n. ${ }^{\circ} 75$ ), y tampoco al que define García de Palacio en su Instrucción náutica, asimismo diverso del que se explica en el Diario. Sin fundamentarlo, Guillén Tato (La parla... cit., s.v.) señala que la palabra «sería la denominación castellana castiza».

47 Sobre papahigo cf. DECH, s.v. Covarrubias no registra la acepción náutica; sí lo hace, en cambio, Autoridades, remitiendo a García de Palacio y a las Décadas de Herrera.

${ }^{4} \mathrm{El}$ DECH registra temporejar como voz náutica tomada del catalán o del portugués. Quizá esta haya sido la forma empleada por Colón en el pasaje citado (el equivalente italiano es temporeggiare), la cual habría pasado por una castellanización debida a Las Casas. El 25 de diciembre aparece temporejar (temporejó), también reemplazado por Las Casas por barloventear. El barloventear usado por Las Casas da cuenta asimismo de a la corda, que el dominico elimina (el 11 de enero el Diario habla nuevamente de estar a la corda y Las Casas explica la acción de barloventear sin usar este término, HI I, pág. 211b). Una explicación diferente de barloventear se encuentra en $H I$ I, pág. $136 \mathrm{~b}$. 
mantiene como designación directa lo que en el texto del Diario era una aproximación comparativa:

antes que llegase al dicho cabo de cinquin con dos leguas hallo vn agrezuela $^{49}$ como la abertura de vna montaña (7 de diciembre).

Antes que llegase al Cabo de Cinquin, con dos leguas, por una abertura de una sierra (HI I, pág. 178b).

En cambio, en otro pasaje, para un objeto referencial próximo Las $\mathrm{Ca}$ sas mantiene angla del texto del Diario, voz que parece ser el primitivo de angrezuela (de fonética aportuguesada) ${ }^{50}$, pero la duplica con abertura, ya presente en la cita anterior:

y a cabo de seis leguas <testado della> hallo vna grande angla: y vido por la tjerra dentro muy grandes valles ( 7 de diciembre).

Andadas seis leguas del Cabo de Cinquín, halló una grande angla o abertura, y vido, por la tierra adentro, muy grandes valles (HI I, pág. 178b).

La variedad de procedimientos de sinonimización puestos en juego por Las Casas se nota en el siguiente ejemplo, en el que la sustitución es sólo momentánea. En efecto, el vocablo técnico colombino es reemplazado, en primera instancia, por una perífrasis de la lengua general, pero inmediatamente después recuperado en un enunciado metalingüístico. Compárese:

porque andava mal [La Pinta] de la bolina porque se ayudaba poco dela mezana por el mastel no ser bueno ( 23 de enero).

no andaba [La Pinta] bien a la bolina, porque se ayudaba poco de la vela trasera, que se llama mesana (HI I, pág. 216a).

El fenómeno inverso se comprueba cuando es Las Casas quien propone el término técnico, no usado por Colón, como en el caso de casi isla, que Las Casas sustituye por península ${ }^{51}$, con alusión explícita a la lengua de la cosmografía, y añadiendo luego la formulación colombina:

\footnotetext{
49 Debe de faltar una $n$ por error, como conjetura Alvar.

${ }^{50}$ Angla «ensenada» parece provenir del portugués angra con el mismo significado, pero la documentación no avala, según Alvar (Diario II, pág. 73, n. 157), la mayor antigüedad de la voz en portugués, razón por la cual prefiere considerar angla un semicultismo. Quizá el diminutivo podría apoyar la interpretación portuguesista.

51 Peninsula aparece como palabra latina en Nebrija (Vocabulario de romance en latín, $\mathrm{s}$. peñiscola) como equivalente de peñiscola, casi isla. La primera documentación que da el DECH en español es de 1611. Hay que señalar que peninsula aparece ya como anotación de Las Casas al margen del Diario.
} 
$\mathrm{y}$ vide vn pedaço de tjerra que se haze como isla (14 de octubre).

Esta manera de tierra llaman los cosmógrafos península, que quiere decir cuasi isla (HI I, pág. 147a).

Quizá el carácter de presuntos extranjerismos que tienen ciertas voces de la escritura colombina motivan a Las Casas a sustituirlas por sinónimos. Que el dominico estaba atento al hecho de que el español del Almirante tenía anomalías debidas a su carácter de lengua no materna se puede comprobar - aparte la observación explícita sobre la repercusión de esta circunstancia en su escritura ${ }^{52}$ - en muchos detalles de la conversión textual que hace el dominico, más allá de los casos de las duplicaciones que estoy analizando aquí. Me permitiré abrir un paréntesis para ilustrar este hecho con el caso de bonanzo. En mi opinión, cuando Colón en el Diario usa bonanzo como adjetivo está calcando el uso del italiano bonaccio (o bonaccioso), aunque no se puede excluir que, concurrentemente, se tratase de un uso de la lengua marinera, como piensa Alvar, si bien el testimonio aducido podría ser materia de otra interpretación sintáctica ${ }^{53}$. La primera vez ocurre el 18 de septiembre:

llevaba en todos estos dias mar muy bonanço como en el rio de Sevilla

Y luego el 5 de octubre:

la mar bonança ${ }^{54}$ y llana a dios dize muchas gracias sean dadas

Las Casas debe de haber reconocido el carácter no castellano de este uso adjetivo pues las dos veces lo corrige en la Historia de las Indias cambiando el uso adjetivo en sustantivo. La primera corrección da un resultado transparente:

${ }^{52}$ Cf. HI I, pág. 172a. Luego de una larga cita textual tomada del Diario, Las Casas comenta: «Todas estas son palabras formales, aunque algunas dellas no de perfecto romance castellano, como no fuese su lengua materna del Almirante».

${ }^{53}$ El dicho marinero «viento en popa y mar bonanza, navega hasta Sancho Panza» (Diario II, pág. 41, nota 60 ), además de ser único, puede ser interpretado, efectivamente, en forma análoga a como interpreto el pasaje de Las Casas citado a continuación en el texto, es decir, suponiendo una construcción elíptica, en la que falta la preposición en o con, con lo cual bonanza sería sustantivo. No hay otros ejemplos del presunto uso adjetivo de esta voz.

${ }^{54} \mathrm{La}$ última sílaba de esta palabra no se lee bien, pues las dos letras aparecen casi fundidas en una. Se reconoce, no obstante, un resto de la cedilla de $c$ y luego una $a$, que Dunn y Kelley leen como $o$. En todo caso, si fuese una $o$, la corrección de Las Casas tuvo el mismo propósito, a saber, eliminar el adjetivo. 
llevaba todos estos días el mar bonanza, como el río de Sevilla. (HI I, pág. 130b-131a).

La segunda corrección es más compleja y significativa: para garantizar el uso sustantivo, Las Casas, según mi interpretación (que subrayo con la coma en la cita siguiente), arriesga una construcción de carácter elíptico (equivalente a «El mar con bonanza», «El mar estaba en bonanza») y suprime, sacrificando así la apreciada dupla léxica que se encontraba en el Diario, el adjetivo llana, cuya presencia en este implicaba la correspondencia categorial con bonanza. He aquí la versión de Las Casas:

La mar, bonanza: muchas gracias sean dadas a Dios, dice aquí Cristóbal Colón (HI I, pág. 137a).

Volviendo a las sinonimias léxicas, cabe advertir que, por cierto, el extranjerismo puede ser a la vez' un término técnico de marinería. Es quizá el caso de voltejar, de interpretación no del todo clara ${ }^{55}$. El pasaje en el que aparece en el Diario es el siguiente:

en este rio podia [sic] los navios boltejar para entrar y para salir y tienen muy buenas señas (o marcas ( 29 de octubre).

Autoridades da el vocablo como catalanismo náutico, pero bien podría ser un italianismo en Colón. En cualquier caso, Las Casas lo sustituye por voltear $^{56}$, atento al posible semantismo y a la raíz común:

En este río de Mares podían los navíos muy bien voltear para entrar a surgir, el cual tiene buenas señas y marcas para que atinen los navíos; (HI I, pág. 157a).

Otros casos son, asimismo, poco claros en lo que respecta al origen del presunto extranjerismo. Alvar ha señalado la posibilidad de un origen portugués de refetar $^{57}$ usado por Colón en el registro del correspondiente al 16

\footnotetext{
${ }^{55}$ En efecto, según Guillén Tato ( $L a$ parla... cit.), significa «navegar ciñendo dando bordos alternativos o sucesivos». Alvar (Diario II, pág. 89, nota 196) anota «voltear». En la documentación antigua, por ejemplo en Pedro Tafur, el significado del verbo parece acercarse más bien al de barloventear.

${ }^{56}$ Curiosamente, en la narración del cuarto viaje, Las Casas utiliza voltejar («El puerto es muy grande y muy hermoso; entró en él por medio de dos isletas, y dentro de él pueden llegarse las naos muy en tierra y salir voltejando si quisieren», $H I$ II, pág. 61a). En vista de este testimonio, y ya que no he podido consultar el manuscrito, cabe la sospecha de que en el pasaje comentado arriba Las Casas haya respetado el verbo colombino y de que se trate de un error de la edición moderna.

${ }^{57}$ Cf. Diario II, pág. 65, nota 139.
} 
de octubre en el sentido de «regatear» - verbo este último usado por Las Casas como sustituto en la Historia de las Indias (I, pág. 149a)-, pero es un asunto que todavía queda abierto. Lo mismo vale para ese cogujo de algodón en el registro del 4 de noviembre, palabra ajena al léxico de Las Casas, quien la reemplaza por capullo. Cogujo, en efecto, no tiene documentación castellana, aunque hay formas emparentadas con el mismo fonetismo $^{58}$.

Sin duda del portugués viene el faxoes utilizado por el Almirante el 4 de noviembre y reemplazado por Las Casas por frisoles o atramuces (HI I, pág. $162 \mathrm{~b})^{59}$. También es portuguesa la voz corredio, usada en el Diario el 13 de octubre con referencia a los cabellos lisos o lacios de los indígenas, la cual da origen a un correntio en el texto de Las Casas (HI I, pág. 144b). No puede tratarse de un error de lectura de Las Casas en este pasaje, como se ha pensado, pues en la relación del tercer viaje, vuelve a hablar, a propósito de los indígenas, de sus cabellos «todos correntíos» (HI I, pág. $355 b$ ), y es de suponer que allí también esté partiendo del portuguesismo señalado. Me parece que puede tratarse de un intento de castellanización por parte de Las Casas, a partir de otros derivados de correr con -en-.

Finalmente, Las Casas debe de haber percibido como extranjerismo también asensar (asensar la anima) en el registro del 14 de febrero, pues lo reemplaza por asegurar (HI, pág. 219b):

asi que (dize) que no deviera temer dicha tormenta / mas su flaqueza y congoxa (dize el) no me dexava asensar <testado su> <interlineado la> anjma $^{60}$.

Retomando el hilo de la motivación relativa a la eventual insatisfacción de Las Casas respecto de la propiedad o adecuación referencial del uso colombino, podemos señalar algunos casos de sustitución, sea unimembre, sea bimembre.

\footnotetext{
${ }^{58}$ Cf. DECH s. cogulla.

${ }^{59}$ Cf. Alvar, Diario I, pág. 12. En la relación del cuarto viaje, Las Casas habla en un pasaje referido a comidas indígenas de «diversas especies de frisoles, que son como habas» (HI II, pág. 57a).

${ }^{60}$ Tres líneas antes de aquella en la que aparece asensar, Las Casas había anticipado la línea por error, razón por la cual debió tacharla. Debajo de la tachadura de la palabra en cuestión se lee asentar. Con respecto a asensar, no encuentro documentación tampoco en italiano, pero puede ser un derivado de senso, con el sentido de «aquietar». En todo caso, si lo que quiso copiar Las Casas es asentar y no asensar, tampoco esa voz le resultaba apropiada al contexto. Sin embargo, empleos metafóricos de asentar que se ajustan al sentido de la frase se encuentran en varias lenguas romances.
} 
El 9 de octubre el Diario registra que

toda la noche oyeron passar paxaros

y Las Casas reemplaza oyeron por sintieron en su Historia:

sintieron toda la noche pasar pájaros (HI I, pág. 138b).

La explicación de esta preferencia sinonímica quizá esté en el carácter más abarcador que podía tener sentir respecto de oir desde antiguo, lo cual lo hacía preferible para aludir a una percepción más amplia y general ${ }^{61}$. ¿Será, en efecto, que Las Casas lo consideró más adecuado porque el pasar de los pájaros los marineros no sólo lo oyen sino lo ven, aun si se trata de horas nocturnas?

Otra sustitución de formas verbales es más fácilmente motivable. En efecto, cuando Colón dice:

mas todavia tengo determjnado de yr a tierra firme y a la çiudad de Quisay y dar las cartas de Vuestras Altezas al gran can y pedir respuesta y venjr con ella (21 de octubre),

Las Casas, en el pasaje correspondiente de la Historia de las Indias (HI I, pág. 153a) reemplaza venir por volver. En verdad, el uso colombino corresponde, no al significado deícticamente restrictivo de 'movimiento hacia el lugar de la primera persona', que es el que predomina en el español moderno, sino a aquel otro más amplio que abarca el 'movimiento hacia el lugar de la segunda o de la tercera persona', presente en varias lenguas y dialectos romances, y también en español medieval, con prolongaciones hasta el Siglo de Oro. El reemplazo de Las Casas, sin embargo, me parece sintomático del proceso de cambio que en el siglo XVI se estaba operando hacia la limitación deíctica de venir en el español moderno.

El siguiente caso de sustitución bimembre de una voz del Diario no deja de suscitar cierta perplejidad, ya que no parece haber nada que reprochar al uso colombino. En efecto, a su llegada a las Azores, el Almirante no se explica la acogida hostil de la autoridad portuguesa y especula sobre la posible causa:

${ }^{61}$ Cf. DECH s. sentir: «muchas veces se trata de una aproximación relativa y sentir valía solamente como expresión genérica que incluía cualquier amplia y vaga percepción por los sentidos, incluyendo el del oído, y aun con predominio de éste». En el Quijote II, XLIV «sintió y oyón. Pero hay otros contextos de esta misma obra donde parece haber equivalencia. 
lo cual [las palabras descomedidas del capitán de la isla de Santa María de las Azores] ojdo el almirante ovo muncho sentjmjento y <testado temio> $<$ interlineado diz que> penso si avia passado algun desconçierto <testado diz que $>$ entre vn rejno y otro despues de su partida (19 de febrero).

Las Casas sustituye desconcierto por alboroto y daños («o hobiese habido algún alboroto o daños entre ambos reinos», $H I \mathrm{I}$, pág. 22b), lo que -más allá de la dupleta léxica - no parece mejorar el texto del Almirante. Quizá si la motivación del dominico haya que buscarla en el carácter no enfático de la voz usada por Colón para aludir al estado de las relaciones entre ambos reinos ibéricos y en un propósito de dar mayor fuerza a las razones de la conducta del capitán de la isla, situando dichas relaciones en una etapa posterior y más grave respecto del solo desconcierto ${ }^{62}$.

Hay varios pasajes del texto del Diario respecto de los cuales Las Casas apela a una sinonimia sustitutiva en su versión de la Historia de las Indias por razones de clara raíz estilística. En efecto, estas sustituciones atienden a evitar reiteraciones léxicas en un contexto limitado, o a evitar palabras muy frecuentemente repetidas en el texto colombino. El primer caso ocurre cuando Las Casas reemplaza diformes por diferentes en un pasaje en el cual el primer adjetivo se halla otras dos veces, ambas respetadas por Las Casas. Veamos:

$\mathrm{Y}$ vide muchos arboles muy diformes de los nuestros [...] y vn ramito es de vna manera y otro de otra y tan disforme [...] aqui los peçes son tan disformes de los nuestros qu'es maravilla (16 de octubre).

Vido aquí muchos árboles muy diferentes de los de Castilla [...] y un ramito de una manera y otro de otra, y tan diforme [...] También dijo que había en aquella mar disformes maneras de peces (HI I, pág. 149b-150a).

También la sinonimia al servicio de la variatio y la duplicación explica la sustitución de brava por la pareja alta o impetuosa con referencia al mar de Cuba, ya que Colón había usado poco antes, en la frase anterior, el adjetivo bravo:

dize que es aquella ysla la mas hermosa que <testado nunca se vido> ojos ayan visto: llena de muy buenos puertos y rios hondos y la mar que

${ }^{62}$ Desconcierto, por lo demás, se halla en el Vocabulario español-latino de Nebrija con las equivalencias confusio, perturbatio. 
pareçia que nunca se devia de alçar: porque la yerva de la playa llegava hasta quasi el agua lo cual no suele llegar donde la mar es brava / hasta entonces no avia experimentado en todas aquellas yslas que la mar fuese brava (28 de octubre).

Tierra llena de puertos maravillosos y grandes ríos; la mar sin algún temor de tormenta, la señal de lo cual es estar la hierba hasta el agua salada crecida, la que no suele haber donde la mar es brava, y hasta entonces nunca vido señal que en todas aquellas islas la mar fuese alta o impetuosa (HI I, págs. 155b-156a).

Asimismo, unas canales de Las Casas reemplaza a unas entradas de Colón en un pasaje del registro del 20 de diciembre, ostensiblemente por la circunstancia de que el Almirante repite en un contexto breve por cinco veces la raíz entr-:

Oy <interlineado al poner del sol> entro en un puerto qu'estava entre la ysla de sancto Thomas y el cabo de Caribata y surgio / este puerto es hermosissimo y que cabrian en el quantas naos hay en xristianos la entrada d'el pareçe desde la mar jmpossible a los que no oviesen en el entrado: por vnas restringas de peñas que passan desde el monte hasta quasi la ysla y no puestas por orden: sino vnas aca y otras aculla vnas a la mar y otras a la tjerra por lo qual es menester estar despiertos para entrar por vnas entradas (20 de diciembre).

Jueves, 20 de diciembre, al poner del sol, entró en un puerto [...]; la entrada dél [...] por lo cual es menester abrir los ojos para entrar por unas canales (HI I, pág. 188a).

En cambio, con la sustitución de diversas por desemejables (registro del 6 de noviembre; HI I, pág. 162b) se evita, no una palabra repetida en el mismo entorno, pero sí reiterada abundantemente en el Diario $^{63}$, en beneficio de otra ausente de este texto.

Pasaré a examinar, en esta penúltima sección, los casos de sinonimia que se encuentran en el texto del Diario, con lo cual reabro el abanico de problemas que toqué en la sección introductoria.

Hay, en primer lugar, aquellos casos en los que Las Casas en la Historia de las Indias opera una reducción del texto del Diario, en el sentido de suprimir uno de los vocablos de la pareja sinonímica presente en este últi-

${ }^{63}$ Quince veces la raíz divers- con diversos morfemas actualizadores. 
mo. Teniendo en cuenta la comprobada afición de Las Casas por la duplicación léxica, la renuncia a ella no puede ser sino significativa. Veamos si es posible aducir alguna motivación.

Un primer caso se presenta en la siguiente descripción de parte de la costa de Cuba:

y navegando adelante hallo vn cabo que salia muy fuera y çercado de baxos y <testado hallo $>$ vido vna concha / o baya donde podian estar navio $[s i c]$ pequeños (31 de octubre).

La Casas aquí retiene solamente bahía en su texto, dejando de lado la palabra concha /kónka/, que consideraría, con razón, como extranjerismo (un portuguesismo o italianismo, con $h$ latinizante), desconcertante para el lector castellano ${ }^{64}$. En cambio, a continuación, duplica el ya comentado encabalgar, anticipándole doblar ${ }^{65}$.

Creo que una explicación semejante de la reducción tiene este otro caso, en el que el texto del Diario presenta una articulación léxica trimembre para un accidente geográfico. Dice así el pasaje:

quedavale vna gran scisura o abertura / o abra a la mar que le pareçio ser rio (6 de diciembre).

Aquí lo que queda suprimido en la Historia de las Indias es el primer término, scisura, un crudo latinismo en español, pero que en Colón más bien debe de provenir del italiano ${ }^{66}$. Dado el carácter trimembre de la sinonimia, la reducción deja intacta la apreciada articulación bimembre (aunque con distinta posición de las voces, «abras o aberturas», HI I, pág. 177b) ${ }^{67}$.

Todavía a propósito de accidentes geográficos, el 25 de noviembre el Diario se refiere a un cabo o punta:

antes del sol salido entro en la barca y fue a ver vn cabo / o punta de tjerra (25 de noviembre).

pero inmediatamente después se habla de «la entrada del cabo». Las Casas, en la Historia de las Indias, uniforma, conformándose con esta última posibilidad y suprimiendo el rastro de la primera vacilación acerca de la na-

\footnotetext{
${ }^{64}$ Cf. sobre esta voz el DECH, s.v. cuenca.

65 Vid. el ya citado y comentado pasaje de HI I, pág. 158a.

${ }^{66}$ Corominas, DECH, s.v. escindir documenta por primera vez cisura en Palencia. En italiano está testimoniado desde el s. XIII (cf. C. Battisti, G. Alessio, Dizionario Etimologico Italiano, Firenze, Barbèra Editore, 1951) y es corriente hasta hoy.

${ }^{67}$ No sería de extrañar que en el original colombino se encontrara sólo scisura y que los dos términos siguientes provengan de Las Casas.
} 
turaleza del accidente geográfico aludido, ya que, en verdad, no hay equivalencia, en sentido estricto, entre punta y $c a b o^{68}$.

Diversa tiene que ser la evaluación de la supresión del segundo vocablo cuando el texto en el Diario informa el 27 de noviembre de la intención de Colón de "aver lengua o pratica» con los indígenas. Frente a la gran cantidad de ejemplos en el Diario de la expresión aver lengua «comunicarse, hablar», que tiene el carácter de fórmula fija, este es el único en el que se rompe ese carácter en virtud de la geminación. Así parece haberlo advertido Las Casas (sea que la geminación se deba a Colón, sea que provenga de él mismo) al redactar la Historia de las Indias, pues conforma esta ocurrencia de la fórmula al tenor del resto.

Quizá el carácter arcaizante e impropio por la connotación militar que implicaba es el que indujo al dominico a suprimir batalla $^{69}$ (optando sólo por gran multitud de gente, HI I, pág. 182a) en el siguiente contexto del Diario:

al tiempo que toda aquella gente estava junta con los xpistianos: vieron venjr vna gran batalla / o multitud de gente con el marido de la muger que avia el almirante honrrado (13 de diciembre).

Para un último caso que mencionaré no tengo sino una hipótesis de corte estilístico. Perdida la Santa María en la Navidad del 92, Colón se consuela con los regalos del cacique. Dice el Diario entonces:

el almirante resçibio mucho plazer y consolacion d'estas cosas que via y se le templo el angustia y pena que avia resçibido y tenja de la perdida de la nao (26 de diciembre).

Las Casas refunde el pasaje del siguiente modo:

Era inestimable el placer, gozo, consuelo y alegría destas cosas que vía, dando gracias a Dios muy intensas por todo, e iba desechando el angustia rescebida de la pérdida de la nao (HI I, pág. 197b).

Se puede conjeturar que la reducción de la pareja angustia y pena del texto de base se produce como compensación de la marcada amplificación si-

\footnotetext{
${ }^{68}$ Curiosamente, parece tratarse de la Punta de Mangle.

${ }^{69}$ Hago notar que en la narración del tercer viaje, Las Casas, citando palabras de Colón, dice: «Estos indios, luego que aquí fueron (dice el Almirante), diles cascabeles y cuentas y azúcar, y los envié a tierra, adonde estaba dellos una gran batalla...» (HI I, pág. 357b). Esto podría hacer pensar que también en el Diario solo batalla proviene de la pluma del Almirante, mientras que el resto - justamente lo que pasa a la Historia de las Indias - se debe a Las Casas.
} 
nonímica anterior, que convierte placer en placer y gozo, y consolación en consuelo y alegría. En este contexto de remodelación estilística bastante fuerte va perdida otra pareja, avia rescibido y tenía, en favor de un final más remansado que, de algún modo, espejea la distensión del ánimo del protagonista.

Junto a estos casos de reducción, hay otros de mantenimiento (si bien, a veces, con modificaciones leves, particularmente en el orden de los términos, cuando no con alguna sustitución). Veámoslos, sin detenernos en todos.

Pasan inmodificados, o casi, del texto del Diario a la Historia de las Indias: señas o marcas (aunque con $y$ en Las Casas) ${ }^{70}$, palpandolos atentandolos (con inversión y conjunción $y$ en Las Casas) ${ }^{71}$, taso o taxo ${ }^{72}$, atarazana o ramada ${ }^{73}$ (con inversión de orden) ${ }^{74}$. Finalmente, un caso de mantenimiento de la estructura geminada con sustitución de uno de los miembros, a saber, escurana, voz sentida probablemente como arcaica por Las Casas ${ }^{75}$ :

por la gran cerraçon y escurana ${ }^{76}$ que el viento y la mar causavan $(21 \mathrm{de}$ febrero).

70 «En este rio podian los navios boltejar para entrar y para salir y tienen muy buenas señas (o marcas)» (29 de octubre); «podían los navíos muy bien voltear para entrar a surgir, el cual tiene buenas señas y marcas» (HI I, pág. 157a).

71 «despues salieronse los hombres: y entraron las mugeres y sentaronse de la misma manera en derredor dellos besandoles las manos y los pies palpandolos atentandolos si eran de carne y de guesso como ellos» (6 de noviembre); "Desde a un rato, saliéronse todos los hombres, y entraron todas las mujeres, las cuales se asentaron alrededor dellos, como habían hecho los hombres, y todas las que podían los atentaban y palpaban si eran de carne y de hueso como ellos» (HI I, págs. 161b-162a). Advierto que en el texto del Diario la palabra palpandolos aparece al final de la línea, fuera de la caja de escritura, como si hubiese sido añadida después; por lo demás, no se lee completa, ya que el pronombre enclítico sólo se reconoce en parte, faltando, por lo menos, las dos últimas letras del mismo.

72 «hallaron los marineros vn animal que pareçia taso / o taxo» (16 de noviembre); «Hallaron los marineros diz que un animal que parecía taso o taxo» (HI I, pág. 168a).

73 «y alli hallo vna almadia / o canoa hecha de vn madero tan grande como una fusta de doze bancos muy hermosa varada debaxo de vna <interlineado ataraçana / o > ramada hecha de madera y cubierta de grandes hojas de palma» (27 de noviembre); "y allí hallaron una canoa de un madero, tan grande como una fusta de doce bancos, muy hermosa, varada debajo de una ramada o atarazana hecha de madera y cubierta de grandes hojas de palma» (HI I, pág. 172a)

${ }^{74}$ Cabría mencionar, aunque no se trata de un caso de verdadera equivalencia, flaquexa $y$ congoxa en el registro del 14 de febrero, porque tiene la particularidad del agregado dize él de Las Casas en la HI I, pág. $219 \mathrm{~b}$.

${ }^{75}$ Es palabra que se usa hasta hoy en varios países de América, cf. DECH, s. oscuro; vid. también Alvar, Diario II, pág. 231, nota 460.

${ }^{76}$ Dunn y Kelley creen que podría leerse también escuranza; por mi parte, leo claramente escurana (como Alvar y otros editores). 
por la gran niebla y cerrazón que había, que causaba la espesura del terrible viento (HI I, pág. 223a).

De los casos citados el que llama más la atención es el de taso o taxo, que pasa inmodificado y que, más que una pareja sinonímica, es una pareja de variantes formales. En efecto, taso (mod. tasso) es el derivado italiano del latín tardío TAXO, que en castellano dio tejón. Siendo un animal bastante conocido y con nombre antiguo en la lengua ${ }^{77}$ - si bien es verdad que existen para él otras designaciones con raíz similar- es extraño que Las Casas, por lo menos en la Historia de las Indias, no sustituyera el conjunto, o al menos taxo, por la designación castellana más común. No es fácil aclarar este mínimo enigma. ¿Encontró Las Casas taso o taxo ya en la copia del Diario que utilizaba y se satisfizo entonces con la equivalencia propuesta? ¿Mantuvo literalmente esta equivalencia en su Historia de las Indias porque él mismo no establecía la relación con tejón? ¿O se trata más bien de una equivalencia, taso o taxo, producida por él mismo en el Diario, echando mano del latinismo, y luego conservada por la misma razón anterior en la Historia de las Indias? Difícil pronunciarse. Diré, sin embargo, que no me resulta plausible atribuir a Colón una duplicación que plantea dos variantes lingüísticas diacrónico-formales, a saber, el vocablo italiano explicado por el étimo latino. Me parece que el Almirante no exhibe preocupaciones idiomáticas que nos orienten en este sentido.

Claro que esta hipótesis desemboca en un espacio más amplio de especulación. En efecto, teniendo en cuenta la predilección de Las Casas por la duplicación léxica como ornato retórico; teniendo en cuenta, además, la orientación explicativa, didáctica y crítica de su escritura, orientación que se expresa en los numerosos comentarios internos y externos en el Diario (y también de modo más amplio y diversificado en la Historia de las Indias) y que consiste a menudo en explicaciones léxico-semánticas y enciclopédicas; teniendo en cuenta, asimismo, los numerosos casos en los que una palabra del Diario aparece duplicada en la Historia de las Indias, cabe sospechar que por lo menos parte de las duplicaciones del propio texto del Diario provenga del dominico y no de Colón ${ }^{78}$.

\footnotetext{
77 Cf. DECH, s.v.

78 A los mencionados elementos de juicio podrían sumarse algunos indicios gráficos del texto del Diario en los puntos en los que aparece una duplicación léxica: en varios casos, como se ha visto en los ejemplos señalados, aparece una barra transversal antes del segundo sinónimo, o en alguno, como es el de señas o marcas ya citado, una especie de paréntesis en vez de la barra, signos que podrían ser interpretados en el sentido de una adición del resumidor. Pero, en contra de dar un peso demasiado fuerte a la presencia de estos signos, hay que decir que su empleo no es sistemático a lo largo del texto. Por lo demás, sería necesario un análisis gráfico de otros manuscritos de Las Casas para poder establecer las correla-
} 
En realidad, las duplicaciones que se encuentran en el Diario son de carácter similar a las que se hallan en la Historia de las Indias. Bien se sabe que la versión resumida, parafraseada, comentada, parcialmente citada, en la que Las Casas salvó para la posteridad el Diario del primer viaje colombino, está concebida y planeada ya como una preparación de la escritura posterior de la Historia de las Indias, más libre de las ataduras de la copia-resumen. Es natural que las tendencias de la escritura lascasiana se encuentren en ambos textos. Frente a palabras poco comunes, por una razón $\mathrm{u}$ otra, Las Casas, tanto en el Diario como en la Historia, a veces define y a veces duplica sinonímicamente con intención explicativa, según los varios procedimientos y con los distintos matices que se han ido viendo a lo largo del presente análisis. Por cierto que la escritura más meditada y reposada de la Historia lleva a corregir, a suprimir, a ordenar diversamente lo que en el urgente proceso de la versión para uso privado del Diario -resumen heteróclito e hirsuto lingüísticamente - no había sido posible limar.

Es evidente que en el marco y límites de esta especulación controlada - controlada en el sentido de apoyada en un conjunto de indicios generales y particulares - no se puede señalar qué parejas sinonímicas presentes en el Diario se deben a Colón y cuáles salieron de la pluma de Las Casas. Pero, por lo menos, este conjunto debe llevarnos a tratar con cuidado la cuestión del léxico colombino y a extremar la prudencia frente a los vocablos que aparecen en estas estructuras bimembres (o trimembres en algún caso). Por ejemplo, puestos ante la dupleta atarazana o ramada, no se puede atribuir, sin más, ramada al léxico del Almirante, de quien, en cambio, probablemente proviene atarazana, por ser término marinero: Las Casas podría haber agregado ramada en el Diario con la intención inclusive de eliminar atarazana, que luego recupera, sin embargo, en la interlínea ${ }^{79}$; después, en su propia escritura de la Historia, optaría por poner en segundo lugar el término más específico ${ }^{80}$.

Hay casos en los que la dupleta léxica del Diario no pasa a la obra de Las Casas, porque en el pasaje respectivo el dominico no sigue de cerca el texto de su versión-resumen, de modo que sólo tenemos el testimonio del Diario: p. e. basa o arena limpia, sondaresa o plomada (ambos en el re-

\footnotetext{
ciones pertinentes. En otros casos, también señalados, da la impresión de que el sinónimo fuese un añadido posterior que intenta aclarar la voz usada en el Diario o recuperar un vocablo del Diario que en primera instancia se había querido suprimir (es la interpretación que sugiero para atarazana, véase más adelante).

${ }^{79}$ Cf. nota 73.

${ }^{80}$ Atarazana «arsenal de navíos» es, en efecto, un antiguo arabismo de ámbito marinero, documentado desde el siglo XIII en español, y con formas paralelas - también de documentación antigua - en otros romances (por ej. cat. drassana, it. darsena, arsenale). Cf. al respecto DECH s.v.
} 
gistro del 6 de diciembre). Ahora bien, sondaresa no puede ser sino de Colón, que conoce la versión aportuguesada de la voz ${ }^{81}$. Pero ¿plomada? $\mathrm{Al}$ comentar sondaresa, Guillén Tato le atribuye una confusión a Colón: «Se ve que confunde la plomada con el cabo» ${ }^{82}$. ¿No será acaso, más bien, una 'confusión', si lo es, de Las Casas? En suma, mal se concibe al experimentado marino estableciendo erradas y erráticas (por aisladas) equivalencias de terminología marinera; y mal se lo concibe, en general, ejercitándose en propuestas metalingüísticas de diversos alcances. Las Casas, en cambio, escribe desde otra condición vital, para otro receptor, con otro propósito y con otro sentido de la lengua. Al dominico se puede atribuir claramente el gusto por la geminación léxica, didascálica y retórica, gusto que, como el de tantos de sus contemporáneos, está en las antípodas de la sensibilidad estilística de nuestros días que invita a «eludir los sinónimos, que tienen la desventaja de sugerir diferencias imaginarias» ${ }^{83}$.

${ }^{81} \mathrm{La}$ forma castellana es sondaleza. Cf. al respecto el DECH, s. sondar.

${ }^{82}$ Cf. La parla... cit.

${ }^{83}$ Jorge Luis Borges, Elogio de la sombra (Prólogo), en Obras completas, Buenos Aires, Emecé, 1976, pág. 975. 